\title{
La Policía Nacional EN EL POSCONFLICTO
}

RAFAel JimÉnEZ VeGA*

\section{Resumen}

Hoy en día, ante la transformación del contexto colombiano, surge la necesidad de transformar a la Policía Nacional para que recupere su esencia civil, distanciándose de las formas militares que se vio en la necesidad de asumir por causa del conflicto interno, el cual, condicionado por las políticas represivas del concepto de la seguridad nacional, terminó desviando la atención sobre la seguridad ciudadana, fundamento indiscutible de la existencia de este organismo, para atender la amenaza guerrillera y el narcotráfico. Hoy se deben orientar los esfuerzos por crear un servicio cívico, con una policía empoderada en el conocimiento creciente de su profesionalismo, y por esta vía crear sinergias que permitan establecer mecanismos que tiendan a fortalecer el civismo y a modificar las conductas anómicas características de los colombianos.
Palabras clave: policía, seguridad, civismo, sociedad, convivencia.

\section{THE NACIONAL POLICE IN THE POST- CONFLICT}

\begin{abstract}
In the present time and given the transformation in national context, the need to transform the National Police arises, to regain its civil essence and to distance itself of the military forms needed on the past and because of the internal conflict, which was conditioned by the national security repressive policy concept ending up and diverting attention of the public safety; indisputable foundation of this body's existence to attend the guerrilla's and drug trafficking threats. Today the efforts should be guided to create
\end{abstract}

* Doctor en Estudios Políticos. Oficial retirado de la Policía Nacional de Colombia (Colombia). rafaeljimenezv68@hotmail.com

Recibido: 21/09/2016/ Modificado: 15/11/2016/ Aceptado: 20/11/2016.

Para citar este artículo

Jiménez Vega, R. (2017). La policía nacional en el posconflicto. OPERA, 20, pp. 85-105.

DoI: https://doi.org/10.18601/16578651.n20.05 
a civic service in which a police empowered with knowledge can increase their professionalism, and in this way create synergies that lead to the establishment of mechanisms that tend to strengthening the citizenship and to modify the characteristics the Colombian anomic behavior.

Key words: Police, security, citizenship, society, coexistence.

Una de las inquietudes que asalta este nuevo escenario nacional son las transformaciones de las instituciones del Estado encargadas de preservar la convivencia de los ciudadanos, como es el caso de la Policía Nacional que, sin lugar a dudas, debe recuperar su esencia civil distanciándose de las formas militares que se vio en la necesidad de asumir por causa del conflicto interno, el cual, condicionado por las políticas represivas del concepto de la seguridad nacional, terminó desviando la atención sobre la seguridad ciudadana, fundamento indiscutible de la existencia de este organismo, para atender la amenaza guerrillera y el narcotráfico. Hoy, con este giro histórico que representa la desmovilización del grupo guerrillero Fuerzas Armadas Revolucionarias de Colombia (FARC), se debe realizar una prospectiva sobre lo que debe ser la Colombia del posconflicto, conjeturando que se deben orientar los esfuerzos por crear un servicio cívico en el que una policía, empoderada en el conocimiento creciente de su profesionalismo, cree sinergias con la sociedad, las autoridades político-administrativas y la empresa privada estableciendo mecanismos que tiendan a fortalecer el civismo y a modificar las conductas anómicas ${ }^{1}$ características de los colombianos.

Hay que comprender que la institución de policía está orientada a la preservación de la convivencia ${ }^{2}$, lo que implica comprender la cultura, el comportamiento de la sociedad y la protección de los recursos; es una institución mediadora, para lo cual se apoya en la educación y la prevención, teniendo como último recurso la fuerza; su fundamento es la ciencia de policía, que es una disciplina autónoma de la civilidad jurídica de la convivencia ideal humana (Londoño, 2011, p. 25). La doctrina de la seguridad nacional rompió con este principio en el contexto de la Guerra Fría, en la que se combatían las diferencias ideológicas con unos criterios militares de amigo-enemigo. Este modelo fue acogido por Colombia después de la Segunda Guerra Mundial, en el que se identifica un enemigo interno, al que se debe perseguir porque sus conceptos políticos son una amenaza para la estabilidad del Estado. Bajo estos parámetros, la Policía Nacional fue reestructurada, debiendo asumir la responsabilidad de la seguridad de una urbanización que iba en ascenso por

\footnotetext{
1 La anomia es un concepto perteneciente a la tradición teórica de la sociología que significa la ausencia de normas, la tendencia transgresora de las reglas (Reyes, 2016, p. 29).

2 La convivencia es la vivencia entre los seres humanos donde hay paz, entendimiento, respeto mutuo y fraternidad (Londoño, 2011, p. 55).
} 
el giro económico, político y social que acompañó este momento histórico del país, pero también se encuentra con unos problemas de orden público en los que la amenaza guerrillera y los atentados sufridos la llevan a que sus integrantes reciban instrucción militar y adopten, en consecuencia, procedimientos de esta índole.

Por el contrario, el concepto de seguridad ciudadana toma la seguridad básica del ciudadano promedio como un referente, es incluyente y participativo, es decir, es democratizante, es una construcción que une el discurso oficial y la experiencia popular para interpretar los peligros sociales y la mejor forma de controlarlos (Whitehead, 2011, p. 230). Como lo refiere Medina Ariza (2011, p. 20), es un modelo comunitario, en el que la toma de decisiones y las estrategias se fijan desde abajo (comunidad), considerando igualmente que no es suficiente tomar medidas para reducir la delincuencia, sino que también se deben incluir las subjetividades creadas por los sentimientos de inseguridad. Se debe tener en cuenta que el sistema de policía y justicia está en la capacidad solo de ser eficiente frente a una pequeña fracción de la población, por consiguiente, para que el modelo sea exitoso, se requiere que las personas practiquen unas formas de autolimitación comportándose con civilidad, en donde el bienestar del otro sea el reflejo de mi propio bienestar, lo que obliga a convivir dialógicamente, comprendiendo por esto un diálogo igualitario en el que las diferentes personas aporten argumentos basados en pretensiones de validez y no de poder.

Por su parte, el Estado debe crear mecanismos eficientes para cumplir su misión de preservar el orden, lo que incluye la protección, tutela y garantías públicas ejercidas para asegurar que los factores primarios como la vida, el aspecto social y la política se encuentren orientados hacia el fin de lograr la convivencia ${ }^{3}$ en la que está inmersa la seguridad (Londońo, 2007, p. 95). En palabras de Chevallier (2011, p. 97), se implementaría la idea de protección de los individuos contra los riesgos de toda clase a los cuales se encuentran expuestos, para que haya una comunidad de justicia y orden. Lo que no es otra cosa que el Estado de derecho propuesto por Kelsen (1934), ampliado posteriormente por Heller a Estado democrático social de derecho, lo que ocasiona que la seguridad sea un objeto existencial de la administración pública.

Esta seguridad se debe garantizar con base en el concepto de policía, como lo afirma Andrea Cavalleti (2010, p. 162), por ser el más alto concepto de la sociedad, pues esta existe para garantizar a cada uno de sus integrantes la conservación de su persona, de sus derechos y de su propiedad, lo que lleva a unir protección y sociabilidad como fines del Estado. Para lo cual se requiere, mantener las diferentes ramas del Gobierno en armonía y a la población educada, siendo esto de vital importancia para crear buenos hábitos, que unidos a la correcta administración crean el camino a la seguridad.

3 La convivencia está conformada por la seguridad, la tranquilidad, la moralidad y el medio ambiente o la ecología (Londoño, 2011, p. 17 ). 
Por ello, el principio del poder de policía que limita las libertades es una herramienta que se debe aplicar en última instancia, privilegiando los métodos y las estrategias preventivas, que conlleven trascender a una condición de seguridad (régimen de policía) (Lleras, 2009, p. 33), pues cuando ya se ha vulnerado el derecho, es la acción represiva del poder judicial la que entra en funcionamiento, fracasando el Estado en su misión de garantizar la convivencia. Es precisamente ahora, cuando se da un paso importante para alcanzar la paz con la desmovilización de un grupo guerrillero y se piensa que este es el fin del conflicto armado, que se debe recordar el concepto de policía que históricamente ha sido el medio mediante el cual el Estado forja y ordena la población civil. Para Neocleous (2010, p. 15) este es un concepto tan importante para la teoría social y política, como lo son soberanía, legitimidad, contrato social $y$ otros de relevancia, que se utilizan para referirse a la organización del Estado. Es de esa "policía" que depende, en buena parte, la felicidad de una nación.

Compréndase, en consecuencia, que este es el fundamento del principio de la co- rresponsabilidad en que se basa la seguridad pública ${ }^{4}$, siendo el ente de policía el que pasa a cobijar a todo el Estado, y en especial a sus gobiernos, que termina comprometiendo a todos los habitantes para lograr el objetivo de alcanzar la convivencia ideal. Este es el mismo argumento del concepto de seguridad ciudadana, pues es absurdo que se pretenda que el cuerpo de policía asuma la responsabilidad de la seguridad pública de manera unilateral, sin el concurso de toda la administración pública y de la participación de la sociedad civil $^{5}$. Porque tal como lo refiere Neocleous (2010, p. 29), la mejor forma de comprender el significado de policía es como una función ${ }^{6}$, dado que la clave de esta ciencia rectora del hombre es que sea considerada como una institución para el mantenimiento del orden en la sociedad, asegurando así la convivencia. Se hace especial referencia a que su razón no radica tan solo en mantener o reproducir el orden, sino en crearlo.

Ahora, con base en este marco teórico, se procede a desarrollar una propuesta de modelo cívico de seguridad, iniciando por explicar sus fundamentos, para continuar posteriormente con la respuesta institucional del Estado ante

4 La seguridad pública implica que los habitantes de un país convivan en armonía, sin temor a ser vulnerados en su integridad física y en sus bienes, respetando los derechos de sus congéneres.

5 Para conceptualizar a la sociedad civil se acude a Hegel para quien "la persona concreta, la cual, en cuanto particular, es a sí misma finalidad, como una totalidad de necesidades vitales y una mezcla de necesidad natural y de arbitrio, es el principio primero de la sociedad civil. Pero la persona particular en cuanto está esencialmente en relación con otra particularidad semejante, de suerte que cada una se hace valer y se satisface por la otra y a la vez simplemente solo mediante la forma de la universalidad, el otro principio se mediatiza el otro principio se mediatiza" (Hegel, 2000, p. 251).

6 El modelo de integración por medio de la intervención del Estado es desarrollado en la teoría de la policía (Cohen y Arato, 2000, p. 132). 
las nuevas demandas de seguridad; por último, se propone una modalidad cívica del servicio de policía, que demanda profesionalismo y aumento de capacidades de todos los integrantes de la institución.

\section{HACIA UN NUEVO MODELO DE SEGURIDAD}

El cuerpo de policía ha sido facultado con destrezas y capacidades para afrontar las complejas labores del control del delito, pero no puede ser el único garante de la seguridad, porque así como lo advierte Marcelo Fabián Sain (2010, p. 29), en primer lugar, el concepto de policía integra una red de agencias y organizaciones estatales y sociales que intervienen de diferentes maneras en los ámbitos de la prevención, conjuración, investigación y punición de los delitos, y que determinan con su interacción la configuración institución policial y su gravitación social; en segundo lugar, la policía tiene una capacidad limitada para generar efectos preventivos, conjurativos y represivos concretos sobre la complejidad y diversidad de los delitos. Esto explica que la criminalidad se deriva de unos fenómenos sociohistóricos que obedecen a unas condiciones sociales, culturales, económicas o políticas difícilmente abordables en toda su complejidad por el cuerpo de policía, lo que lleva a considerar que la seguridad es un proceso que se produce y reproduce a través de un conjunto complejo de interacciones en el que el uso de la fuerza como respuesta a las violencias y agresiones son el último recurso, porque la alternativa no violenta se ha consti- tuido en la principal acción preventiva como medio de intervención, en donde el conjunto de la sociedad conforma el principal factor oferente de seguridad.

Se debe asumir que el Estado no lo puede todo, de allí que se requiera una mayor continuidad entre la acción individual y la acción colectiva, lo que Pierre Rosanvallon (1995, p. 214) llama un reformismo del individuo, fortaleciendo los principios organizadores de la solidaridad, para ofrecer un marco satisfactorio en el cual pensar la situación de los excluidos. Esto hace que la cultura y los hábitos de los ciudadanos jueguen un papel trascendental. Por consiguiente, para Adriana Cavarero (2009, p. 45), se hace obligatorio que se convoque a la responsabilidad colectiva en la construcción de la convivencia, transformando así la preocupación narcisista de la melancolía en preocupación por los demás.

Este nuevo contexto cívico lleva a considerar que la dependencia del Ministerio de Defensa dificulta el accionar de una estrategia de seguridad ciudadana, en donde no tiene cabida el ámbito militar, porque esta no se consolida con fusiles, sino con dispositivos policiales destinados a la prevención del delito y de todas las actividades que afecten el normal desarrollo de la vida diaria de los ciudadanos; es claro que el orden interno de un país debe ser orientado con una visión civilista, en un proceso donde la participación de la sociedad civil y de la acción individual se hacen indispensables, para crear las condiciones de convivencia necesarias en un mundo globalizado, en donde el concepto de seguridad obliga a ir más allá de la intervención del Estado. 
Ha habido históricamente una ambigüedad entre las tareas de protección de la ciudadanía y de defensa del orden constitucional, producto de la subordinación de las primeras a las segundas, en virtud de la implementación de la doctrina de la seguridad nacional. Así lo advierte Álvaro Camacho Guizado (2014, p. 338), para quien esto ha significado una pérdida de identidad de la policía al desviar su papel original en la estructura del Estado, adoptando un perfil militar que incrementa el alejamiento del ciudadano, convirtiéndose incluso en oportunidades en un agente de represión política, en donde ya no es el ciudadano, sino el orden público lo que se privilegia, orientando su estrategia a la liquidación de la oposición armada y la delincuencia y no a la protección de la ciudadanía. Por esto existe la necesidad de reconocer la radical distinción entre las características de la Policía Nacional y las Fuerzas Militares, aclarando que los militares protegen la integridad de la Nación y el orden constitucional con base en la defensa y la guerra, y los policías tienen la función de proteger al ciudadano y de garantizar el libre ejercicio de sus derechos.

Se debe tener en cuenta que el modelo de seguridad cambió al transformarse humano, haciendo que haya más factores que atender, porque ya no es suficiente con brindar la seguridad física, que era atendida por el Estado con un concepto tradicional, que con base en legislación y el cuerpo de policía, establecía estrategias que se adaptaban al contexto social manteniendo la convivencia. Ahora, se hace mucho más complejo satisfacer las demandas de seguridad, lo que ha llevado a que se deban atender diferentes factores que han surgido con la globalización, donde las fronteras son porosas y vulnerables, deslocalizando el delito, causando por consiguiente su transnacionalización. Hoy en día, una sociedad activa debe ayudar a la construcción de su convivencia, se debe contar con un ciudadano comprensivo y tolerante por voluntad propia para causar la sensación de sentirse seguro, y esto lo debe lograr el individuo en una sociedad contemporánea cuyo concepto de seguridad vive en constante cambio debido a que cada día se incrementan los métodos para romper el estado de seguridad, apareciendo en este sentido múltiples amenazas que al ser impredecibles repercuten en el desarrollo de las actividades donde intervienen el individuo y la sociedad en su conjunto (Serrano, 2008, p. 66). Así, son los argumentos humanos, morales y éticos los que confrontan las amenazas, y no ceden ante las influencias negativas de una población marginal mediatizada.

Por consiguiente, existe la necesidad de entender la seguridad de una manera contraria a la vertiente convencional o tradicional, que se caracteriza por establecer solo aspectos estratégico-militares, en una sociedad que no está en capacidad para hacerle frente a las nuevas amenazas y riesgos que tienen de manera creciente un carácter transnacional, no necesariamente estatal ni militar. Por esto, indica Alejo Vargas (2008, p. 255), toda estrategia debe partir de un ámbito democrático incluyente y participativo, con una óptica regional e internacional, incluyendo a los diferentes grupos, comunidades y organizaciones sociales en los que prima el respeto por los derechos humanos, económicos, políticos y sociales, de acuerdo con lo pregonado por un Estado social 
de derecho, en el que no se deben presentar inseguridades en estos aspectos, de tal manera que lo importante es que el individuo sienta que puede actuar libremente en búsqueda de su propio desarrollo humano y del progreso colectivo, en una sociedad moderna democrática. Colige Pedro Medellín (2014, p. 149), que cuando la policía pierde el componente de civilidad, deja de ser referente social sobre la materia, respondiendo esto a la militarización de la institución, algo que nació desde su adscripción al Ministerio de Defensa, y posteriormente se ha fomentado en parte por la presión política por producir resultados, lo que va en contravía de su esencia, que debe promover la civilidad, el buen orden y la tranquilidad de los asociados.

Este concepto de la seguridad conlleva al cambio en las relaciones entre la sociedad y el Estado, es un contexto político que hace relevante la participación ciudadana en la construcción de políticas públicas de seguridad. Este argumento se encuentra en el Preámbulo de la Declaración y Programa de Acción de Viena de 1993, en donde se afirma que la persona no es solo el principal beneficiario de los derechos, sino que debe participar activamente en su realización, lo cual se ratifica en el Convenio de Aarhus el 25 de junio de 1998, que afirma la participación pública en la toma de decisiones y acceso a la justicia en temas medioambientales de la United Nations Economic Commission for Europe (UNECE); de igual manera, en la Declaración de las Naciones Unidas en su Resolución de la Asamblea General del 8 de marzo de 1999, donde se afirmó el derecho y el deber de los individuos, los grupos y las instituciones de promover y proteger los derechos humanos y las libertades fundamentales universalmente reconocidas, ligando el fortalecimiento de los derechos humanos a la participación activa de las organizaciones de la sociedad civil, de los medios de comunicación y de los propios sujetos en su promoción, defensa y divulgación.

En consecuencia, el proceso que obedeció a la necesidad de preparar a la policía contra las constantes agresiones de la guerrilla, debe ahora dar paso a una institución más preparada para liderar a una sociedad participativa y crítica del accionar de las instituciones del Estado, donde la imposición es rechazada al considerarse como sinónimo de autoritarismo. Es así como se termina dando paso al control civil a todas las acciones estatales, porque la sociedad se superpone quedando como razón de la existencia del Estado. De esta manera, la protección del ciudadano pasa a ser el fundamento de las políticas de seguridad, y la prevención el principal recurso para evitar el crimen, dejando la represión como última alternativa por implementar, porque como indican Camacho y Guzmán (2014, p. 403), los actos violentos se ubican en el terreno de la imposición y generan rechazo.

Por consiguiente, se debe orientar la atención en la acción y la estructura social, porque es allí donde se crean espacios en los que las dimensiones económicas causan atracos, robos, secuestros, defensa de la propiedad, narcotráfico y deudas; por tanto, en el campo de la política surge la necesidad de crear estrategias que reduzcan la inequidad y la desigualdad, restando motivos a la lógica criminal; lo que también incluye comprender el ámbito donde surgen las identidades que 
se construyen a partir de modelos simbólicos y relacionales, que muchas veces causan conductas desviadas, produciendo el ajuste de cuentas por violaciones de las relaciones personales manifestadas en pandillas, barras deportivas, violencia familiar, en la sexualidad y en la marginalidad que degenera en homicidios hacia los estigmatizados sociales. Por consiguiente, es evidente que las acciones eminentemente represivas son ineficientes en un ámbito tan complejo, que implica una acción articulada de la institucionalidad del Estado con la sociedad, para solucionar las causas que afectan la convivencia.

La figura 1 muestra el total de delitos causados en el territorio nacional desde 1970 , partiendo de 130.000 para ir aumentando de manera sostenida hasta superar los 200.000, nivel en el que se estabilizaron hasta el siglo xxi; es llamativo cómo asciende el número de delitos después del 2000, mostrando que el
Plan de Seguridad Democrática 2002-2010 no tuvo los resultados esperados, precisamente fue en este periodo donde más se aplicó la acción coercitiva para mejorar las condiciones de seguridad.

Aunado a estas estrategias fallidas del Estado, Camacho y Guzmán (2014, p. 407) hacen alusión a lo perjudicial que ha sido en el contexto colombiano la acumulación, la dominación y la intolerancia, que han dado como resultado los antagónicos a estos: supervivencia, rebeldía y exigencia de reconocimiento, dimensiones que se configuran en los campos de conflicto económico, político y social, y se constituyen en claves que permiten fragmentar la estructura social para su estudio, porque así se pueden interpretar las manifestaciones y modalidades de violencia. Estas situaciones acontecen en una sociedad que acepta de manera tácita las diferencias entre quienes poseen, mandan o niegan las

FIGURA 1. COMPORTAMIENTO DEL TOTAL DE DELITOS 1970-2005

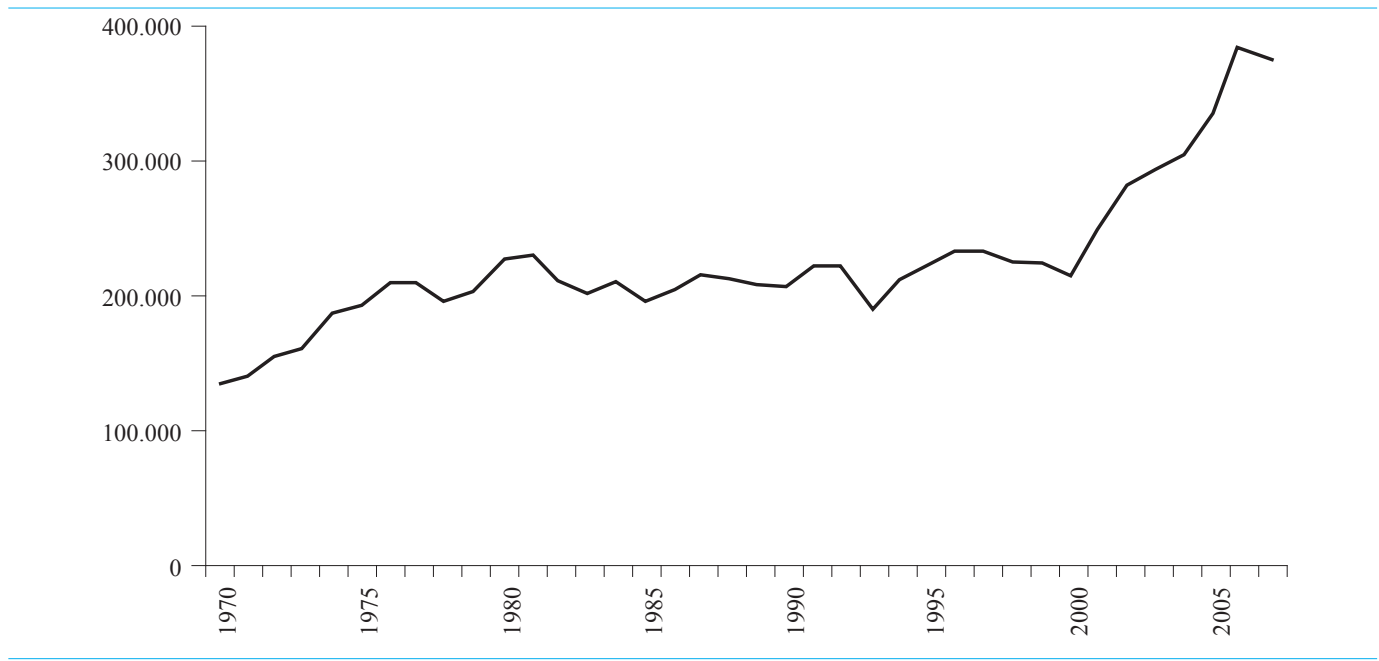

Fuente: Policía Nacional, CIC-DIJIN (Acero y Pérez, 2008, p. 67). 
identidades de otros, y de quienes carecen, obedecen y no tienen reconocimiento de sus identidades sociales, por no ajustarse a los cánones morales dominantes.

Se debe en consecuencia realizar un seguimiento a las causas que originan los conflictos y las conductas desviadas, porque las fuentes de inseguridad son diversas; por tanto, para su solución se requiere de una amplia gama de herramientas entre las cuales, sin lugar a dudas, se encuentra la obediencia a las normas y la disciplina que debe tener cada ciudadano para no afectar el ejercicio de las libertades de los demás, demandando esto una constante reflexión cívica sobre los peligros que pueden acechar la convivencia, lo que conlleva una acción colectiva que ejerza un control social y articule esfuerzos con las instituciones del Estado.

Este nuevo enfoque es un camino que hay que asumir, porque a lo largo de la historia colombiana se ha podido apreciar que las políticas impositivas de seguridad solo han logrado construir muros de resistencia, propiciando que el recurso a la violencia se normara como pauta de conducta para la solución de conflictos, que en otras circunstancias podrían haber sido resueltos pacíficamente acudiendo a la acción comunicativa (Camacho y Guzmán, 2014, p. 408). Pero para llegar a este punto se debe fortalecer la cultura cívica en la que se implementen controles éticos y morales como mecanismo para transformar las tradiciones y las costumbres a fin de fortalecer, por este medio, los marcos institucionales que otorgan el derecho a disentir y a diferenciarse, tolerando la existencia de desigualdades y contradicciones sin recurrir a la violencia.
Por esto, el enfoque debe ser multisistémico, para prevenir, controlar y enfrentar los riesgos (amenaza más vulnerabilidad). Alejo Vargas (2006, p. 254) señala que se debe controlar la exposición de la sociedad a las amenazas, aumentando su capacidad de resistencia y respuesta por medio del fortalecimiento sus estructuras económicas y físicas, porque la seguridad ya no debe ser entendida con el concepto tradicional de seguridad y defensa nacional enmarcado en una óptica de carácter militar, sino que esta debe ser democrática, es decir, que debe estar enmarcada en una concepción cívica que indique tolerancia, solidaridad y respeto por las diferencias, siendo incluyente en los ámbitos económico, político, social y cultural. De esta manera se minimizan las amenazas en busca de una normalidad. En contraste, la defensa nacional tiene que ver con los recursos económicos y humanos del país, así como con las políticas necesarias para garantizar la seguridad en términos de soberanía, independencia, integridad y mantenimiento del orden constitucional, siendo este un concepto estado-centrista que remite necesariamente al uso de estructuras de fuerza. Muy por el contrario, lo que se requiere es que se amplíe la agenda con la incorporación de nuevos ámbitos como el económico, el político, el social y el ambiental, lo que trae como consecuencia una construcción de la seguridad con enfoque en las necesidades sociales.

Hay que tener en cuenta que las ciudades y las zonas rurales no crean problemas de seguridad por sí mismas, sino que los conflictos sociales surgen a partir de determinaciones que se desarrollan en lo económico, lo político y lo ético (Camacho y Guzmán, 2014, p. 
412), nutriendo fenómenos delincuenciales que afectan la convivencia, que solo la acción integrada de la institucionalidad del Estado puede llegar a contener y controlar teniendo como complemento la participación ciudadana, lo que debe ser un objetivo central de la reflexión política, porque de esta manera se relacionan las partes con el todo. Para Criado de Diego (2014, p. 14), esta forma de colaboración humana a través de la cual un grupo se autoorganiza genera instancias de decisión, dirección o gestión que legitiman todo lo que se acuerda. Por ello, al hacer parte la Policía Nacional del proceso, se hace trascendental que legitime su acción para evitar los desórdenes sociales, por ser una de las herramientas esenciales en la construcción de un Estado con capacidad de regular y dirimir los conflictos a partir de la ley y de los arreglos institucionales democráticamente establecidos. Incluso hay que anotar, que la policía en su misión de conservar el orden social, al mismo tiempo lo reproduce (Camacho, 2014, p. 360).

Hay que tener en cuenta que, hoy en día, los modelos de seguridad afrontan el reto de encontrar un equilibrio en el dilema entre libertad y orden, porque las acciones mediáticas con visos represivos del Estado se pueden convertir en problemas perdurables de seguridad y en un reto para la gestión policial, situación de la que es difícil salir si el orden social en sí mismo no tiene a la democracia, la justicia y la convivencia como sus principios rectores (Camacho, 2014, p. 361). Sin lugar a dudas, la seguridad requiere de una sociedad activa y crítica, lo que significa la existencia de una responsabilidad colectiva frente a las diferentes demandas, fijando obligaciones al individuo que permitan a las personas inhibirse de percibir a los otros y a sus actos como amenazas latentes (Ruiz y Manrique, 2006, p. 217).

Por consiguiente, no basta con fortalecer al cuerpo de policía para llegar a niveles adecuados de seguridad, sino que la comunidad debe tomar conciencia de que su rol va más allá del elemental cumplimiento de las normas de convivencia, requiriéndose en consecuencia de sus integrantes crear hábitos profilácticos, en los que se tenga conciencia de que sus acciones y omisiones afectan o benefician el bienestar de los demás, y que eso, como un efecto espejo, termina reflejándose en su propia calidad de vida. Por ello, la respuesta a las nuevas demandas de seguridad no solo puede provenir de un cuerpo de policía, sino de la construcción de saberes sociales que propicien la convivencia (Habermas, 2002, p. 35).

Lo que se ha descrito hasta ahora no es otra cosa que el concepto de civilidad, que corrige los comportamientos bárbaros, desordenados o inmorales, transformándolos en actos que conducen al buen orden. Al ser este el origen y la naturaleza de la institución policial, se debe en consecuencia formular políticas efectivas que respondan a las necesidades y demandas de la sociedad para solucionar los problemas de inseguridad, haciendo indisociables la civilidad y la política, es decir, lo que aquí se expone es un "modelo cívico de seguridad". Para su implementación es necesario que el Estado imparta cátedra de civismo en la educación primaria, porque es allí donde se forman en primera instancia las estructuras mentales; por otra parte, la policía debe realizar campañas de formación en civismo a través de los medios de comunicación, en 
las juntas de acción comunal, en los consejos de administración de propiedad horizontal y organizando grupos juveniles que promuevan el civismo en cada barrio y localidad. Para esto es necesario que todos los miembros de la institución estén comprometidos con la implementación del modelo, todos deben tener la capacitación y estar fomentando en cada oportunidad el cambio hacia una actitud solidaria y cívica.

\section{RESPUESTA INSTITUCIONAL DEL ESTADO ANTE LAS NUEVAS DEMANDAS DE SEGURIDAD}

Ante las nuevas demandas de seguridad el Estado ha respondido con unas políticas públicas, como la incluida en el Plan de Desarrollo 2006-2010 que en el tomo I destina un acápite a la defensa y seguridad democrática, con el objetivo de implementar el Estado de derecho en todo el territorio, incluyendo la participación activa de los ciudadanos; sus tres pilares fueron: la protección de los derechos de todos los ciudadanos; la protección de los valores, la pluralidad y las instituciones democráticas; y la solidaridad y cooperación de toda la ciudadanía. Por otra parte, está la Política Nacional de Seguridad y Convivencia Ciudadana del Gobierno del presidente Santos -que se diferencia por primera vez de las políticas de seguridad nacional-, orientada por la Alta Consejería Presidencial para este efecto con el concurso de las entidades del orden nacional y regional, definiendo la seguridad ciudadana como ...la protección universal a los ciudadanos frente aquellos delitos y contravenciones que afecten su dignidad, su seguridad personal y la de sus bienes, $y$ frente al temor a la inseguridad. La convivencia, por su parte, comprende la promoción del apego y la adhesión de los ciudadanos a una cultura ciudadana basada en el respeto a la ley, a los demás y a unas normas básicas de comportamiento y de convivencia social (DNP, 2014, p. 1).

Son políticas que ha ido desplegando la institucionalidad del Estado en el territorio nacional, algo que históricamente es novedoso en Colombia, porque ante la colonización marginal característica, la población ha quedado desprotegida generando espacios que han propiciado la conformación de grupos al margen de la ley.

Entre otras iniciativas del Estado se encuentra el fortalecimiento del talento humano de la institución policial, que ha crecido y mejorado su capacitación para estar a tono con las crecientes exigencias de la sociedad, porque para ejercer liderazgo se requiere de mentes preparadas que sepan cómo orientar la construcción de la convivencia. Por otra parte, se puede apreciar que los medios económicos asignados a la policía por el Estado se han encaminado a fortalecer la seguridad ciudadana, creando nuevas unidades metropolitanas y fortaleciendo unidades que aportan a la institución para lograr este fin, dadas las necesidades que surgen en una institución que ha crecido y lo seguirá haciendo, porque los problemas de seguridad son de índole policial, por lo que es necesario, para mejorar su servicio, disponer de medios logísticos y tecnológicos imprescindibles para cumplir con la misión constitucional asignada. 
De esta manera fue creciendo el número de integrantes de la Policía Nacional, acorde con las capacidades académicas del común de la sociedad; sin lugar a dudas, la institución policial es el reflejo de la sociedad a la que se debe, por consiguiente, en la medida que fue mejorando la educación nacional, fueron aumentando las exigencias académicas para ser policía.

Se observa que para 1990 había 2.379 oficiales, 4.602 suboficiales y 61.154 agentes, conformando un total de profesionales de policía de 68.135 uniformados; posteriormente, con la Ley 62 de 1993, se crea el nivel ejecutivo que reemplaza a los agentes y suboficiales, por lo cual se observa una disminución en esas dos categorías y un aumento de la categoría emergente, siendo su primer dato de referencia en 1994 con 7.909; para recibir el nuevo siglo en el 2000 con 3.816 oficiales, 2.947 suboficiales, 35.438 nivel ejecutivo y 33.017 agentes, para un total de 75.218 profesionales de policía. Para mayo del 2015, la Policía Nacional estaba conformada por 7.151 oficiales, 137.976 del nivel ejecutivo, 332 suboficiales y 1.958 agentes, para un total de 147.417 profesionales de policía; número que crece hasta 186.382 , al sumarse 4.241 de personal no uniformado, 25.571 auxiliares de policía y 9.153 estudiantes de las escuelas de formación ${ }^{7}$.

Se debe señalar que en este proceso de crecimiento cuantitativo también ha habido una mejora considerable a nivel cualitativo, lo cual obedece a la consideración de que en una organización es esencial el talento humano, por lo cual la Policía Nacional, de acuerdo con la Resolución 01071 del 12 de abril de 2007, establece el protocolo de selección e incorporación, dando cumplimiento al mandato que indica que todo procedimiento gubernamental debe estar sustentado en la Constitución Política Nacional. De esta manera, pasa a definir el enfoque por competencias laborales para la institución, de acuerdo con el perfil del policía definido en el modelo de Gestión Humana, incluyendo en este proceso la incorporación de aspirantes a ingresar a la institución y la selección de uniformados para cursos de capacitación, de acuerdo con las competencias requeridas para prestar los servicios en las especialidades existentes.

Se debe mencionar que la Ley 62 del 12 de agosto de 1993, en el artículo 6 establece que la Policía Nacional estará integrada por oficiales, personal del nivel ejecutivo, suboficiales, agentes, alumnos, por quienes prestan el servicio militar obligatorio en la institución, y por servidores públicos no uniformados. En el artículo 7 de la misma norma se establece que la actividad de policía es una profesión y, por tanto, sus servidores reciben una formación académica integral, permitiendo su promoción profesional, cultural y social, con acento en los derechos humanos, la ética, la ecología, el liderazgo y el servicio comunitario. Es por ello que cada miembro de la institución, de acuerdo con su rango, será capacitado integral-

7 Información aportada por la Oficina de Planeación de la Policía Nacional. 
mente en academias y centros de formación especializados.

Por otro lado, la formación de los uniformados ha mejorado ostensiblemente, egresando de las escuelas con mejor capacitación y mejores fundamentos académicos, incluso dentro de estos claustros se brinda formación en educación superior en pregrado y posgrados. La capacitación del personal policial en pregrados en el año 2007 sumó 346, siguiendo ańo por ańo en un constante aumento, para llegar al 2015 a 1.018 policías. Por otra parte, en lo tecnológico sumaban en el mismo ańo un total de 1.096 , y en la parte técnica un total de 8.129. El proceso de formación de cada uno de los policías incluye la posibilidad de desarrollar posgrados una vez egresados de las escuelas de formación; por ejemplo, las especializaciones se inician en el 2007 con 250 policiales, en el año 2008 son 325, en el ańo 2009 crecen a 422, con un aumento ańo tras año hasta llegar al 2015 a incrementarse en el número de policiales a 756; en el 2011 se inicia el ingreso al nivel de maestría con 28 policías, en el 2012 fueron 14, con un aumento notable en el 2013 con 54, para llegar al 2014 con un total de 87 y en el 2015 con 271 policiales que hacen parte del proceso ${ }^{8}$.

En cuanto a la capacitación en otros centros de educación superior, encontramos que hay un número creciente que viene adelantando procesos académicos por medio de becas, dentro de una política de fortalecimiento del capital humano institucional, que va desde pregrado hasta doctorados, encontrándose al 2015 lo siguiente: 95 policías en pregrado, 116 en especialización, 256 en maestría y 15 en doctorado. A esto se le suman los policías que por propia iniciativa se financian sus proyectos académicos.

Sin embargo, se puede apreciar que la capacitación del personal aún debe mejorar, porque los policías que están recibiendo una formación académica en la educación superior, porcentualmente son un número reducido frente al notorio aumento en talento humano.

\section{LOS NUEVOS ROLES DE LA POLICÍA EN EL POSCONFLICTO}

En primer lugar, hay que señalar que la policía actualmente asumió el reto de apoyar el proceso de paz, para lo cual se creó la Unidad para la Edificación de la Paz mediante resolución presidencial el 22 de abril de 2016, dependiente de la Dirección de Protección y Servicios Especializados, que tendrá a su cargo la seguridad de las 27 zonas de concentración que dispuso el Gobierno nacional para los integrantes del grupo guerrillero FARC, dentro del desarrollo de desmovilización y desarme. También incluye la responsabilidad de brindar protección a los guerrilleros rasos y jefes del grupo guerrillero que abandonen las áreas con permiso del Gobierno, mientras dura el proceso de normalización de los guerrilleros.

8 Información aportada por la Dirección Nacional de Escuelas de la Policía Nacional. 
Es claro que esto es algo mediático y la policía debe proyectarse en el tiempo como una institución garante de la convivencia, lo que en primera medida logrará ejerciendo influencia sobre la sociedad, para lo cual debe consolidar la confianza ciudadana en la institución, lo que implica su dedicación exclusiva a la seguridad de la misma. Esto conlleva, como lo indica Christian Álvarez (2015, p. 216), una mayor sinergia con el Ministerio del Interior y la Rama Judicial, para brindar seguridad en las áreas urbanas y rurales, particularizando estrategias en las zonas de mayor afectación por el conflicto armado. Es claro que esta acción debe ir acompañada de toda la institucionalidad del Estado, generando desarrollo a fin de crear alternativas económicas viables para los habitantes de las zonas que han sido colonizadas marginalmente.

En el área urbana, la policía debe implementar estrategias que inhiban la anomía, es decir, acudir a todos los estratos sociales para que no adapten las normas a su conveniencia, porque si bien es cierto, como indica Víctor Reyes (2016, p. 108), que en la marginación y la exclusión se crean normas para la supervivencia, los miembros de la sociedad más favorecidos deben dar ejemplo de civilidad, porque es muy común que estos integrantes de la sociedad, valiéndose de su posición, transgredan las normas.

Es indudable que en la construcción de la seguridad las personas deben conformar un mejor entorno a partir de los valores colectivos que reúnen los intereses de todos los individuos, definiendo así las relaciones de los ciudadanos, la política y las instituciones, donde cada individuo es responsable de su rol así como el de las instituciones. De esta forma, se crea una dinámica que devela los problemas estructurales correspondientes a las personas, porque son ellas la causa que genera la acción y los mecanismos de regulación.

Por tanto, se debe pensar la seguridad como un elemento que hace parte de las relaciones sociales, ya no es solo el panóptico el que mantiene a los sujetos en una condición disciplinada, ahora el enfoque es el concepto biopolítico, en el que la población asume como cuerpo social la responsabilidad de crear las instituciones informales propicias que faciliten a los individuos el desarrollo de sus capacidades.

Algo vital es desarrollar mecanismos psicológicos que sustenten el sentimiento de confianza, reflejen seguridad durante las actividades diarias de la vida social, es decir, construyan convivencia mediante acciones correctas repetidas como un acto normal de los individuos. Compréndase que cada individuo adopta de manera inmediata una postura en el fluir su vida cotidiana haciendo suyas las instituciones sociales. De esta manera los seres humanos, mediante su comportamiento, determinan una identidad social.

Para esto es indispensable hacer uso de los medios de comunicación, porque tal como lo ilustran Manuel Castells (2006) y ByungChul Han (2014), las antiguas redes de la actividad humana, al transformarse en redes sociales de la información, han facilitado la acción colectiva en una lógica descentralizada de libre información, de coordinación y ausencia de jerarquía que ha permitido el pronunciamiento de innumerables personas, consiguiendo la solidaridad y unión a cada causa en particular, sin ningún compromiso. 
Compréndase que lo que se deben modificar primordialmente son las instituciones informales, porque ellas son sistemas de autoorganización social en los que actúa el contagio mimético (imitación), que como enuncia Mario Solarte (2016, p. 115), se deben amparar en el bien común sin obviar el particular, conformando de esta manera una comunidad que comparte ciertas apreciaciones y comportamientos, en donde el ser humano es consciente de que requiere de afirmar su existencia en el otro.

Esto no quiere decir que la policía inhiba su deber de hacer cumplir la ley, porque como lo acota Mark Kleiman (2015, p. 113), el concentrar los esfuerzos en un pequeño número de malhechores, imponiendo con ello sanciones veloces y certeras, aumentando la probabilidad de que cualquier delito conduzca al castigo, hace que el mal comportamiento sea una opción poco atractiva. Pero el mismo autor aduce, coincidiendo con Robert D. Cooter y Thomas Ulen (2016, p. 651), que el castigo o la amenaza al castigo no son los únicos mecanismos disponibles para controlar el crimen, debiéndose privilegiar al control social para mejorar el dominio de sí mismos y así inhibir los malos actos de los potenciales infractores. Adicional a esto, hay que tener en cuenta que no son solo los actos delictivos los que se deben evitar, sino que son todas las conductas que afectan el orden social, entendiéndose por esto el cumplimiento de las normas que facilitan la vida en comunidad, como son las normas de tránsito, el simple hecho de hacer una fila, controlar el sonido de los equipos de música en los hogares, etc. Se debe partir del principio de que los am- bientes desorganizados tienden al delito, y las conductas anómicas conducen a que no se respeten las leyes formales y se acrecienten los problemas sociales.

Lo acotado hasta ahora lleva a conjeturar que los policías deben mejorar notoriamente su capacitación, no es la cantidad de policías lo que en definitiva mejora las condiciones de seguridad, sino la eficiencia y efectividad del servicio que prestan. El modelo aquí esbozado demanda mayor profesionalismo y preparación por parte de los uniformados, se deben conformar equipos de trabajo con la sociedad, las autoridades político-administrativas y la empresa privada para emprender el propósito de cambiar hábitos y costumbres, para lo cual se requiere conocimiento y ascendencia sobre los ciudadanos, lo que significa que se debe tener autoridad, y ella solo se consigue a través del aumento de las capacidades y del ejemplo.

Por otra parte, en el área rural la responsabilidad está a cargo de la Dirección de Carabineros y Seguridad Rural definida por la Resolución 04245 del 31 de diciembre del 2009, para contribuir al proceso de consolidación del control estatal del territorio, contrarrestando los fenómenos criminales en el ámbito rural; de la misma manera, se pretende con esta dirección articular las capacidades institucionales para el efectivo acompañamiento del proceso de restitución de tierras, y también se le asignó la responsabilidad de establecer parámetros conducentes al efectivo control de la explotación ilegal de la actividad minera, orientados a la protección del medio ambiente, los ecosistemas y los recursos naturales. Para esta tarea cuenta, de acuerdo con información suministrada por la 
Dirección de Carabineros y Seguridad Rural el 20 de octubre de 2014, con 50 escuadrones móviles de carabineros, que son grupos con entrenamiento militar creados para neutralizar la guerrilla y las bandas criminales, a lo que se le adiciona un grupo especial destinado a controlar el hurto de hidrocarburos, sumando en personal 106 oficiales, 437 miembros del nivel ejecutivo o mandos medios, 3.614 patrulleros, para un total de 4.157 uniformados. Para apoyar el desarrollo del sector rural se conformaron los grupos de carabineros y guías, que son policías que prestan su servicio a caballo para brindar seguridad en el campo y apoyar al labriego en la jornada, en un total de 87 grupos, conformados en la actualidad por 115 oficiales, 324 del nivel ejecutivo y 1.056 patrulleros y agentes, entre los que existen 2.526 técnicos agropecuarios para asistir a los trabajadores del campo.

La Dirección de Carabineros y Seguridad Rural es la encargada de garantizar el proceso de restitución de tierras y el retorno a sus lugares de origen de millones de desplazados por el conflicto. Esta dirección es la que debe mantener el orden y la tranquilidad del campo colombiano, no podemos olvidar que es allí donde se desarrolló la mayor parte del conflicto, donde los actores armados impusieron su voluntad ante la falta de presencia efectiva del Estado. Como describe Fernán González (2014, p. 479), el Estado colombiano ha venido integrando de manera algo conflictiva, incluso violenta, nuevos territorios y poblaciones a la vida política y económica del país, por lo cual se ha propuesto garantizar el monopolio estatal del uso de la fuerza, recuperar la capacidad de la justicia para sancionar los delitos, y ampliar el cubrimiento institucional del Estado en el territorio nacional.

Esta responsabilidad debe ir acompañada de un seguimiento a la actividad agraria realizada individualmente por los carabineros, por tanto, deben capacitarse en su totalidad en profesiones y tecnologías agropecuarias para que presten asistencia y ayuda al campesino. Lo que se trata es de hacer equipo y de realizar un trabajo asociado que lleve a la construcción de convivencia. Este contacto le permitirá al policía tener una cercanía con el ciudadano, conocer sus necesidades y tener información oportuna de cualquier irregularidad que pudiera llegar a acontecer. De esta manera, los carabineros serían la presencia efectiva del Estado en el campo, trabajo que desarrollarían en coordinación con las entidades estatales encargadas del desarrollo agropecuario.

Las zonas con actividad económica dinámica, o próximas a los centros administrativos y políticos más importantes del país, son las que más se han afectado por los problemas de delincuencia. Como lo enuncia Echandía (2006, p. 21), los escenarios con abundancia de recursos naturales son de mayor propensión a la violencia y al crimen. Por tanto, se puede entender que para un Estado que basa su economía en la agricultura y en recursos naturales, se hace imprescindible afianzar su presencia en estos sectores, $y$ de esta manera colmar todos los espacios del territorio, evitando dejar vacíos que puedan ser colmados por oportunistas que pretendan imponer arbitrariamente su voluntad.

Es dentro de este marco, que la seguridad ciudadana es aplicada en el campo, pues como lo enuncia Germán Puentes (2008, p. 172), es- 
ta se fundamenta en un conjunto de elementos y de factores de índole político, económico, ambiental, cultural, social e institucional que inciden en la vida de los habitantes, haciendo viable optar a una vida digna. Así, se puede colegir que por conducto de este modelo se garantizan los mínimos de bienestar que el Estado adopta por consenso para todos los miembros de una comunidad por el solo hecho de nacer, residir o habitar su territorio, y de esta manera, cuidar del interés particular como un interés común, en el entendido de que la policía no solo brinda seguridad a los individuos y su propiedad, sino que también se ocupa de su bienestar.

Pero dentro de este contexto hay que enunciar que la policía, como institución, requiere de redes que le permitan aumentar su capacidad, para lo cual, los potenciales ciudadanos locales sirven como complemento a su función, aportando su conocimiento e integrando esfuerzos para lograr la consolidación del orden y, así, establecer relaciones comunales pacíficas que indudablemente se encuentran relacionadas con el desarrollo comunitario y social. Es por esto que la desaparición de la coerción abierta es considerada por Serrano (2008, p. 69) como la mejor alternativa, porque de esta manera los individuos apoyan al Estado que han construido, logrando que se sientan satisfechos de pertenecer a él.

Para lograr estos objetivos, la policía creó el Sistema Integrado de Seguridad Rural (Siser) con el fin de desarrollar una estrategia que permita afectar en primera medida los delitos de mayor impacto como son la explotación ilícita de yacimientos mineros que está devastando el medio ambiente y creando focos de criminalidad, por otra parte, está bajo su responsabilidad el control del hurto de hidrocarburos de los oleoductos que se encuentran a lo largo del territorio nacional y el relevante proceso de restitución de tierras que es fundamental para demostrar que la institucionalidad del Estado hace presencia en el campo. También está contemplada la conformación de grupos de carabineros con sus caballos y perros, entre los cuales hay algunos técnicos agropecuarios para desarrollar el acompañamiento de la labor rural; es fundamental que todos los carabineros reciban esta capacitación, pues en ellos reposaría en últimas la consolidación de la convivencia rural. Sin lugar a dudas, el patrullaje que deberán realizar es indispensable, pero más allá de esto se requiere que el policía se integre con el campesino, lo que se logrará al demostrar idoneidad en las tareas agrarias, algo que acompañado de cortesía y amabilidad lo compenetrará con la sociedad rural.

Es bajo estos supuestos de la civilidad y de la solidaridad, que los ciudadanos podrán sentirse seguros, porque al participar de manera individual o grupal, practicarán un comportamiento político que ayudará a la correcta conducción de la sociedad, lo que de igual manera conlleva al fortalecimiento de la institucionalidad del Estado y a la construcción de la nación. Por ello, al articular esfuerzos las fuerzas vivas de la comunidad rural con los carabineros, se potenciará el campo y se alejará la amenaza.

Por otra parte, y con el ánimo de aumentar el pie de fuerza y orientar recursos destinados a la seguridad ciudadana, se considera 
que la policía podría omitir unos roles que ha asumido, como:

Protección. La Dirección de Protección y Servicios Especializados, creada por Resolución 04244 del 31 de diciembre del 2009, que derogó la Resolución 02062 del 15 de junio del 2007, entre su estructura cuenta con la unidad de Protección a Personas e Instalaciones, como dependencia encargada de liderar y controlar los procesos y medidas adoptadas con el fin de prevenir, minimizar o neutralizar posibles amenazas o atentados en contra de la vida e integridad de personas que por razón de amenazas o de su cargo requieran de un servicio especial de protección y el apoyo de servicios extraordinarios, así como la realización de los estudios de seguridad tanto a personas como a instalaciones; esta área consume muchos recursos humanos y materiales que serían muy útiles en la seguridad ciudadana, incluso los medios que se utilizan técnicamente son superiores a los que emplea el personal de vigilancia. El Estado debería crear un órgano que cumpla con las funciones de esta dirección.

Control del tránsito. Se debe entender que ante el crecimiento de las ciudades la congestión vehicular a aumentado, por lo cual en varias ciudades del país su regulación se entregó a la Policía Nacional. Este es un servicio que lo pueden organizar las alcaldías municipales con cuerpos destinados para este fin.

Servicio de transporte masivo. Por la ausencia de civismo hay personas que vulneran los controles para no cancelar el valor del pasaje; así mismo, aparecen también los delincuentes oportunistas que, aprovechando las aglomeraciones, hurtan los elementos de los pasajeros o, mediante la intimidación de armas, realizan atracos masivos que afectan gravemente la percepción de seguridad; por esto, la policía asumió un rol especial para atender las contingencias delictivas y de movilidad que se presentan en este ramo. Aquí se hace la observación de que varios medios de transporte masivo son de capital privado por lo que, en consecuencia, las empresas deberían asumir la seguridad del sistema.

Control de espectáculos públicos. Los espectáculos públicos desvían la atención de la policía debiendo retirar uniformados de las calles para enviarlos a los lugares de congregación como estadios y coliseos. En los países desarrollados existen empresas privadas especializadas en el manejo de los eventos abiertos al público, como conciertos y eventos deportivos, evitando que la policía descuide la seguridad ciudadana.

Policía de atención de desastres. Para atender los desastres naturales y diferentes tipos de emergencias, se conformó el Grupo de Operaciones Especiales en Emergencias y Desastres (PONAL SAR) de acuerdo con la Resolución 01976 del 8 de junio del 2011, que reestructuró la Resolución 03595 de septiembre del 2014, dependiente de la Dirección de Seguridad Ciudadana. Es de anotar, que en este aspecto puede haber duplicidad de funciones con los bomberos y la Defensa Civil, que son organismos del Estado creados para tal fin.

Sector penitenciario. Se le ha asignado a la institución responsabilidades en este ámbito, incluso nombrando como director del INPEC a un brigadier general, y destinando uniformados para fortalecer este sector. Incluso algunas 
instalaciones de la policía albergan personas privadas de la libertad, algo que no tiene nada que ver con su misión.

\section{CONCLUSIONES}

Para concluir, una vez realizado este breve análisis de la institución policial ante las nuevas demandas de seguridad, se puede apreciar que posee un talento humano que ha crecido y mejorado su formación, pero que aún está lejos de la capacitación que se requiere para asumir su responsabilidad en el nuevo modelo de seguridad; sumado a esto, el porcentaje de uniformados vinculados en los procesos académicos adicionales a su formación obligatoria aún es bajo. Esto se ve reflejado en el presupuesto destinado a la Dirección Nacional de Escuelas, que en lugar de aumentar en proporción al pie de fuerza ha disminuido, siendo esto un contrasentido. Es imperativo que los policías se empoderen en el conocimiento y se profesionalicen para que asuman su papel en un contexto mucho más exigente, que es inclusivo y participativo. De lo contrario, no es posible hablar de un servicio profesional y cívico de policía.

Sin lugar a dudas, el nuevo contexto social demanda de una acción integrada del Estado que adopte un enfoque multisistémico de seguridad, que deje como última opción la acción coercitiva y privilegie la acción preventiva dentro de las estrategias que se desarrollen. Es indispensable contar con la voluntad de las personas para que la dinámica social mejore, y esto se logra realizando actividades de proximidad que cierren las distancias con el ciudadano. Para este efecto se propone el modelo de seguridad cívico, en el que en primera medida el policía debe ser capacitado y luego convertirse en un multiplicador. En este concepto se considera que es la misma sociedad la que edifica su seguridad a través de sus actitudes solidarias y cívicas. Por su parte, la institucionalidad del Estado acompañará el proceso a través del fomento de la educación cívica en las instituciones educativas y la realización de campañas con la policía que manera que se incentive el cambio de actitud en la sociedad; de la misma manera facilitará la infraestructura necesaria para la dinámica económica y la seguridad social requeridas a fin de promover la igualdad y la equidad.

\section{REFERENCIAS}

Álvarez, C. (2015). Reformas y transformaciones de la Fuerza Pública colombiana en un escenario de poscomflicto. En Vargas, A., Garcia, V. (eds.). Seguridady defensa en la transición de la guerra a la paz: reflexiones y perspectivas (pp. 207-229). Bogotá D.C: Universidad Nacional de Colombia.

Acero, M. y Pérez, B. (2008). Los delitos contra el patrimonio en Colombia: comentarios sobre su comportamiento en décadas recientes. Revista de criminalidad 50 años, 50 (1), 67.

Camacho, A. (2014). "Obra selecta” Violencia y conflicto en Colombia (vol. III). Bogotá: Universidad de los Andes.

Camacho, A. y Guzmán, A. (2014). Colombia: ciudad y violencia. En Camacho, A. "Obra selecta” violencia y conflicto en Colombia (vol. III, pp. 397-409). Bogotá: Universidad de los Andes. 
Castaño, A. (1947). La policía, su origen y su destino. Bogotá: Policía Nacional de Colombia.

Castells, M. (2006). La sociedad red: una visión global. Madrid: Alianza.

Cavalletti, A. (2010). Mitología de la seguridad, la ciudad biopolitica. Buenos Aires: Adriana Hidalgo.

Cavarero, A. (2009). Horrorismo, nombrando la violencia contempotánea. Barcelona: Anthropos.

Chevallier, J. (2011). El Estado posmoderno. Bogotá: Universidad Externado de Colombia.

Chevallier, J. (2015). El Estado de derecho. Bogotá D.C: Universidad Externado de Colombia.

Cohen, J. y Arato, A. (2000). Sociedad civil y teoria politica. México: Fondo de Cultura Económica.

Cooter, R. y Ulen, T. (2016). Derecho y economía. México: Fondo de Cultura Económica.

Criado de Diego, M. (2014). Participar, la ciudadania activa en las relaciones Estado sociedad. Madrid: Dykinson.

Departamento Nacional de Planeación. Dirección de Justicia, Seguridad y Gobierno (2014). Política nacional de seguridad y convivencia ciudadana, Recuperado de http://wsp.presidencia.gov.co/ Seguridad-Ciudadana/consejeria/Documents/ Pol\%C3\%ADtica\%20Nacional\%20de\%20 Seguridad\%20y\%20Convivencia\%20Ciudadana-\%20Español.pdf, recuperado: 14 de noviembre de 2.016 .

Echandía, C. (2006). Dos décadas de escalamiento del conflicto armado en Colombia 1986-2006. Bogotá: Universidad Externado de Colombia.

Elias, N. (2009). El proceso de la civilización, investigaciones sociogenéticas y psicogenéticas. Méxio: Fondo de Cultura Económica.

Enzensberger, H. (1994). Perspectivas de guerra civil. Barcelona: Anagrama.

Foucault, M. (2006). Seguridad, territorio, población. México: Fondo de Cultura Económica.
Giddens, A. (2011). La constitución de la sociedad, bases para la teoría de la estructuración. Buenos Aires: Amorrortu.

González, F. (2014). Poder y violencia en Colombia. Bogotá: Antropos.

Gutiérrez, F. (2014). Elorangután con sacoleva, cien años de democracia y represión en Colombia (19102010). Bogotá: Universidad Nacional de Colombia.

Habermas, J. (2002). Teoría de la acción comunicativa, I, Racionalidad de la acción y racionalización social. México: Taurus.

Han, B. (2014). Psicopolitica. Barcelona: Herder.

Hegel, G. (2000). Rasgos fundamentales de la filosofía del derecho o compendio de derecho natural y ciencia del Estado. Madrid: Biblioteca Nueva.

Heller, H. (2004). Teoría del Estado. Granada: Comares. Kelsen, H. (1934). Teoria general del Estado. Madrid: Labor.

Kleiman, M. (2015). Cuando la fuerza bruta fracasa, cómo lograr que haya menos crimen y menos castigo. Bogotá: Universidad de Los Andes.

Lleras, M. (2009). Derecho de policía, ensayo de una teoría general. Bogotá: Escuela de Estudios Superiores de Policía.

Londoño, F. (2007). Analectas para una filosofía policiaca. Bogotá: A.P.I Impresiones.

Londoño, F. (2011). Esbozo de una teoría general de la ciencia de policía. Bogotá: Policía Nacional de Colombia.

Londoño, F. (2012). Excerpta de la convivencia: la seguridad como su primera categoría. Bogotá: Policía Nacional de Colombia.

Medellín, P. (2014). Importancia de la civilidad en la política. En Londońo, F., Estupiñán, L., Gamboa, A. y Cobos (eds.). Memorias tercer congreso internacional de ciencia de policía (pp. 147-150). Bogotá: Policía Nacional de Colombia. 
Medina, J. (2011). Politicas y estrategias de prevención del delito y seguridad ciudadana. Buenos Aires: Euros.

Neocleous, M. (2010). La fabricación del orden social: una teoría crítica sobre el poder de policía. Buenos Aires: Prometeo.

Pajón, A. (2011). Policía y orden público en la regeneración. En Múnera, L. y Cruz, E. La regeneración revisitada, pluriverso y hegemonía en la construcción del Estado-nación en Colombia (pp. 233-283). Medellín: La Carreta.

Pineda, R. (1950). La policía, doctria-historia-legislación. Bogotá: Concejo de Bogotá.

Policía Nacional (2009). Estado y compendio de la convivencia en Colombia. Bogotá: Policía Nacional.

Policía Nacional de Colombia (2.010). Ciencia de policía serie cuadernos 1. Bogotá: Gente Nueva.

Policía, C. (2010). Politica para la consolidación del servicio de policía rural (tomo 2). Bogotá: Policía Nacional.

Puentes, G. (2008). Reflexiones sobre la seguridad ciudadana. En Bonett, M. Seguridades en construcción en América Latina (tomo II, pp. 171-197). Bogotá: Universidad del Rosario.

Reyes, V. (2016). La anomia, espacios, tiempos y conflictos anómicos. Análisis de casos. Bogotá: Aurora.

Ruiz, J., Illera, O. y Manrique, V. (2006). La tenue línea de la tranquilidad, estudio comparado sobre seguridad ciudadana y policía. Bogotá: Universidad del Rosario.

Rosanvallon, P. (1995). La nueva cuestión social, repensar el Estado providencia. Buenos Aires: Manantial.
Sain, M. (2010). La reforma policial en América Latina, una mirada crítica desde el progresismo. Buenos Aires: Prometeo.

Serrano, E. (2008). Una visión de la seguridad. En Bonett, M. Seguridades en construcción en América Latina (tomo II, pp. 58-69). Bogotá: Universidad del Rosario.

Solarte, M. (2016). Violencia e institución, aportes para una ética de la responsabilidad social. Bogotá: Universidad Javeriana.

Torres, C. (2010). Colombia siglo XX, desde la guerra de los Mil Días hasta la elección de Álvaro Uribe. Bogotá: Norma.

Torres, J. (1994). La ciudadanía pacta con su policía: el proceso de modernización de la Policía Nacional de Colombia. En Leal, B. y Tokatlian, J. Orden mundial y seguridad, nuevos desafios para Colombia y América Latina (pp. 173-203). Bogotá: Tercer Mundo.

Torres, R. (1999). Tratado de derecho de policía. Bogotá: Ediciones Ciencia y Derecho.

Vargas, A. (2008). La lenta marcha en el siglo xx hacia un Ejército profesional moderno de Colombia. En Torres, C., Rodríguez, S. (eds.). De milicias reales a militares contrainsurgentes, la institución militar en Colombia del siglo XVIII al XXI (pp. 299337). Bogotá: Universidad Javeriana.

Whitehead, L. (2011). Democratización teoría y experiencia. México: Fondo de Cultura Económica. 